\title{
Need for Animal Models of Meibomian Gland Dysfunction
}

\author{
Louis Tong · Preeya. K. Gupta
}

Received: October 11, 2016 / Published online: November 11, 2016

(C) The Author(s) 2016. This article is published with open access at Springerlink.com

\begin{abstract}
Evaporative dry eye has gained increasing interest in recent years in academia, pharmaceutical, and medical device industries. The main cause of this type of dry eye is attributed to meibomian gland dysfunction (MGD). MGD is a diffuse abnormality of the meibomian glands characterised by terminal duct obstruction and eventually leading to signs
\end{abstract}

Enhanced content To view enhanced content for this article go to http://www.medengine.com/Redeem/0617 F060548478DE.

L. Tong

Ocular Surface Research Group, Singapore Eye

Research Institute, Singapore, Singapore

L. Tong

Corneal and External Eye Disease Service, Singapore

National Eye Center, Singapore, Singapore

L. Tong

Eye-Academic Clinical Program, Duke-NUS Medical

School, Singapore, Singapore

L. Tong $(\square)$

Department of Ophthalmology, Yong Loo Lin

School of Medicine, National University of

Singapore, Singapore, Singapore

e-mail: Louis.tong.h.t@singhealth.com.sg

Preeya. K. Gupta

Duke Department of Ophthalmology, Duke

University School of Medicine, Durham, USA and symptoms of dry eye. There have been only a few reported animal models of MGD, but recent advances are likely to lead to new models and better ways to assess the pathology in these animals. Recent models reported include one based on cautery of the meibomian glands in mice and another based on aggravated allergy in mice. These developments will enable better pre-clinical assessment of novel therapies in the future.

Keywords: Animal models; Dry eye; Meibomian gland dysfunction; Mice; Ocular disease; Pathology; Rat

\section{COMMENTARY}

Dry eye is a common problem worldwide, and it has been reported that $70 \%$ of dry eye has an evaporative component [1]. The major cause of evaporative dry eye is meibomian gland dysfunction (MGD). In MGD, the occlusion of the terminal ducts leads to a cascade of changes including retention of meibomian lipids, abnormal tear lipid layer, signs of evaporative dry eye, as well as atrophy and 
loss of meibomian glands. A recent international workshop by international experts mentioned that there is an unmet medical need in MGD, research in MGD is a priority, and one essential tool for translational research is an appropriate animal model. With increased clinical interest in MGD as it relates to tear stability and tear lipid chemistry, development of an animal model for MGD is paramount. New therapeutic medical devices for MGD are now available. There is increased interest in the development of lipid-containing eyedrops. It is advantageous to evaluate efficacy and safety of these new treatments in pre-clinical studies [2]. Currently available animal models resemble only one or more of these pathophysiological aspects, but are dissimilar to human MGD in other ways, either in the chronicity of the disease or the requirement for glandular occlusion to be the initiating event in the disease. It is important to avoid excessive pain when inducing the MGD features in animals.

An ideal animal model for MGD should include anatomical features of human disease, such as obstruction of the glands, keratinisation of the ducts, and dilatation of the ductules. As in human disease, the observable characteristics should diffusely affect the entire lids in a chronic or progressive manner, with fibrosis or edema of the eyelid margin. Even though the lipids of murine meibum are quite different from humans [3], there is likely biochemical abnormality in the animal tear or meibum that can be measured after induction of disease, such as changes in saturation of wax esters, decreases in O-acyl $\omega$-hydroxyl fatty acids (OAHFAs), or increases in lysophospholipids. Ideally, there should be a high success rate for induction of the MGD, and animals involved should have normal lifespan and have little to no involvement of other systemic organs.

Here we review the features of the reported animal models (mouse and rat) that exhibit abnormalities in meibomian glands (Table 1). Animal models that report primarily blepharits [4] or reflect an ocular surface dessication model with secondary MGD [5] are not included in the discussion. There are some pros and cons for each of the models reported. Several animal models are suitable for evaluation of developmental abnormalities of meibomian glands, for example, a mutation in the EDARadd gene resulted in rats with abnormal meibomian, sweat, mammary, and other exocrine glands [6]. Such models may or may not reflect acquired disease that obstruct the meibomian glands. As MGD is more common in older people, a model that used superoxide dismutase deletion in mice reflects human disease in that these mice also show age-related MGD features. Furthermore, this model also presents with evaporative dry eye features that improved after treatment [7]. Superoxide dismutase is an important enzyme that sequesters free radicals, and in the absence of this enzyme, free radicals tend to increase, which is a phenomenon observed in aging cells and tissues. A mouse model that used cautery was successful in the induction of MGD after 4 and 8 weeks due to induction of post-cautery fibrosis, suggesting that glandular changes were secondary to obstruction [8]. Another model in rabbits using cautery of meibomian glands has also been reported [9]. Two other interesting novel models of MGD include one that is HR-1 mice fed with a lipid limiting diet [10], the other an aggravated allergic model that involved infiltration of eyelid neutrophils and IL17-mediated inflammation [11].

There is much unknown in this exciting research area. Some of the more recent studies 


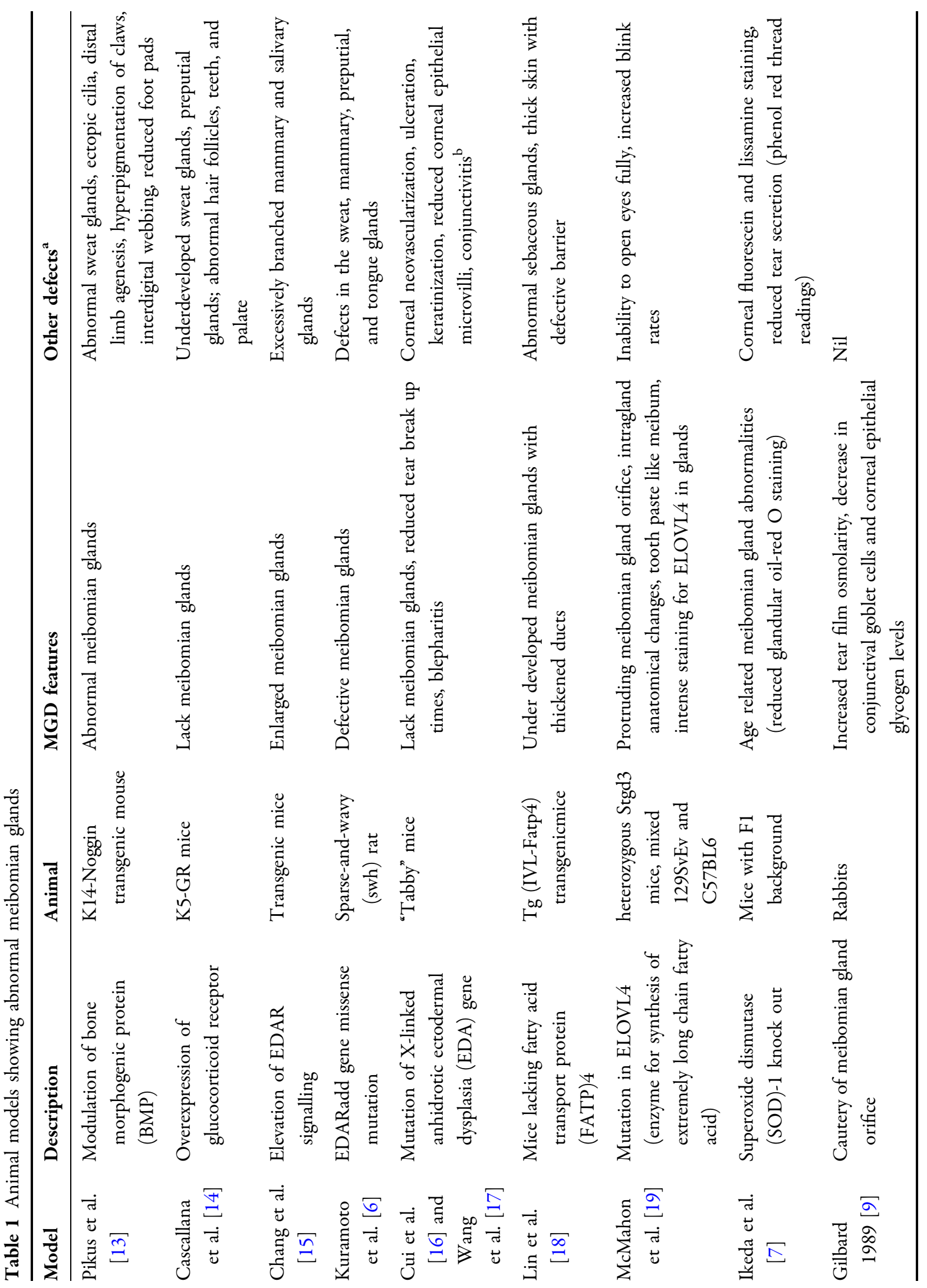




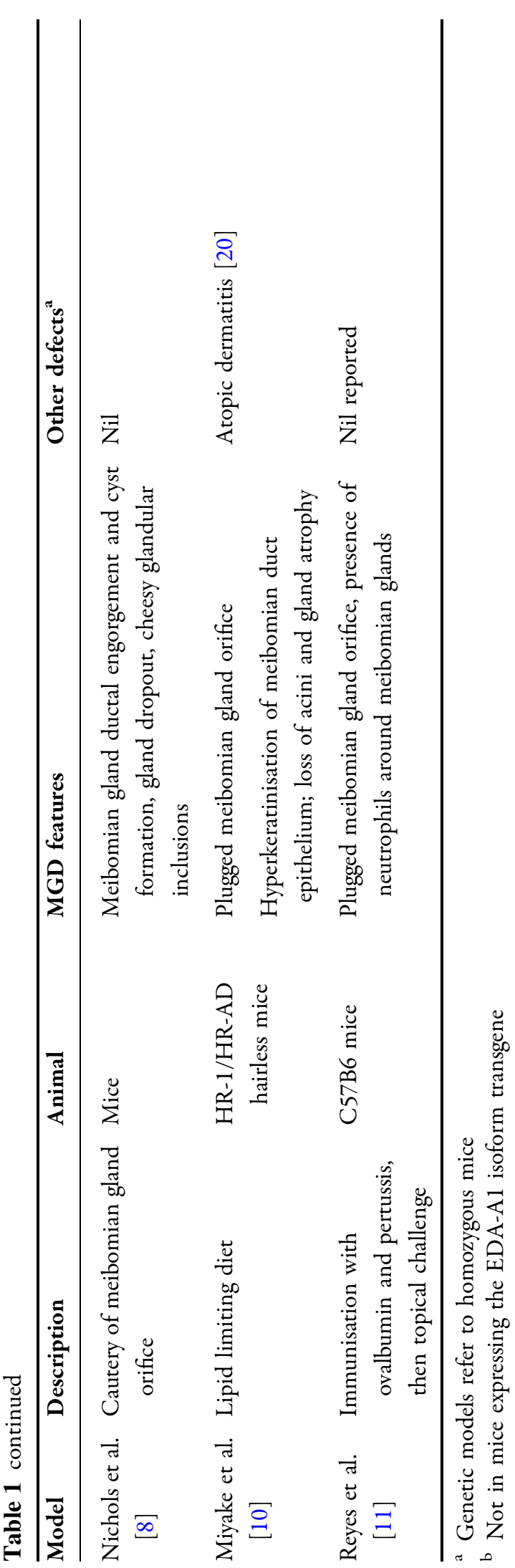

evaluated here have only been reported in conference proceedings, and there is no doubt that the search is ongoing for a better and more convenient animal model of MGD. Newer imaging modalities and robust biochemical techniques will be employed in the evaluation of these future animal models. Novel image analysis algorithms would be useful for in vivo confocal microscopy, which is a non-destructive process. In tissue sections non-linear optical imaging and volumetric analysis of meibomian glands is a promising technique [12]. In cases where inflammation is to be evaluated, observation of leukocytes in two-photon live microscopy may be useful. These novel techniques will likely further our understanding of newer therapies of MGD such as probing and intense pulse light, as to date there are no suitable models to assess the effects of these therapies at the microscopic level.

\section{ACKNOWLEDGEMENTS}

This work is supported by the Grant: NMRC \CSA $\backslash 045 \backslash 2012$ from the National Medical Research Council, Singapore. All named authors meet the International Committee of Medical Journal Editors (ICMJE) criteria for authorship for this manuscript, take responsibility for the integrity of the work as a whole, and have given final approval for the version to be published.

Disclosures. L. Tong and P. Gupta have nothing to disclose.

Compliance with Ethics Guidelines. This article is based on previously conducted studies and does not involve any new studies of human or animal subjects performed by any of the authors. 
Open Access. This article is distributed under the terms of the Creative Commons Attribution-NonCommercial 4.0 International License (http://creativecommons.org/licenses/ by-nc/4.0/), which permits any noncommercial use, distribution, and reproduction in any medium, provided you give appropriate credit to the original author(s) and the source, provide a link to the Creative Commons license, and indicate if changes were made.

\section{REFERENCES}

1. Lemp MA, Crews LA, Bron AJ, Foulks GN, Sullivan BD. Distribution of aqueous-deficient and evaporative dry eye in a clinic-based patient cohort: a retrospective study. Cornea. 2012;31(5):472-8 (Epub 2012/03/02).

2. Geerling G, Tauber J, Baudouin C, Goto E, Matsumoto $\mathrm{Y}, \mathrm{O}^{\prime}$ Brien $\mathrm{T}$, et al. The international workshop on meibomian gland dysfunction: report of the subcommittee on management and treatment of meibomian gland dysfunction. Invest Ophthalmol Vis Sci. 2011;52(4):2050-64 (Epub 2011/04/01).

3. Butovich IA, Lu H, McMahon A, Eule JC. Toward an animal model of the human tear film: biochemical comparison of the mouse, canine, rabbit, and human meibomian lipidomes. Invest Ophthalmol Vis Sci. 2012;53(11):6881-96 (Epub 2012/08/25).

4. Mondino BJ, Caster AI, Dethlefs B. A rabbit model of staphylococcal blepharitis. Arch Ophthalmol (Chicago, Ill: 1960). 1987;105(3):409-12 (Epub 1987/03/01).

5. Suhalim JL, Parfitt GJ, Xie Y, De Paiva CS, Pflugfelder SC, Shah TN, et al. Effect of desiccating stress on mouse meibomian gland function. Ocular Surf. 2014;12(1):59-68 (Epub 2014/01/21).

6. Kuramoto $\mathrm{T}$, Yokoe $\mathrm{M}$, Hashimoto $\mathrm{R}$, Hiai $\mathrm{H}$, Serikawa T. A rat model of hypohidrotic ectodermal dysplasia carries a missense mutation in the Edaradd gene. BMC Genet. 2011;12:91 (Epub 2011/10/22).

7. Ikeda K, Dogru M, Kawashima M, Kojima T, Higa K, Igarashi A, et al., editors. The effect of $3 \%$ diquafosol sodium eye drops on the meibomian gland alterations of the superoxide dismutase-1 knockout mice. ARVO; 2016; 57(12):2869.
8. Nichols KK, Hanlon SD, Nichols JJ, editors. A murine model for characterizing glandular changes in obstructive meibomian gland dysfunction. ARVO; 2014; 55:13:14.

9. Gilbard JP, Rossi SR, Heyda KG. Tear film and ocular surface changes after closure of the meibomian gland orifices in the rabbit. Ophthalmology. 1989;96(8):1180-6 (Epub 1989/08/01).

10. Miyake H, Oda T, Katsuta O, seno m, Nakamura M, editors. Meibomian gland dysfunction model in hairless mice bred under special diet limiting lipid content. ARVO; 2016; 57(12).

11. Reyes N, Saban DR, editors. Pathogenesis of meibomian gland dysfunction (MGD) requires the T cell-neutrophil axis, in the allergic setting. ARVO; 2016; 57(12).

12. Jester JV, Brown DJ. Wakayama symposium: peroxisome proliferator-activated receptor-gamma (PPARgamma) and meibomian gland dysfunction. Ocul Surf. 2012;10(4):224-9 Epub 2012/10/23.

13. Plikus M, Wang WP, Liu J, Wang X, Jiang TX, Chuong CM. Morpho-regulation of ectodermal organs: integument pathology and phenotypic variations in K14-Noggin engineered mice through modulation of bone morphogenic protein pathway. Am J Pathol. 2004;164(3):1099-114 Epub 2004/02/26.

14. Cascallana JL, Bravo A, Donet E, Leis H, Lara MF, Paramio JM, et al. Ectoderm-targeted overexpression of the glucocorticoid receptor induces hypohidrotic ectodermal dysplasia. Endocrinology. 2005;146(6):2629-38 (Epub 2005/03/05).

15. Chang SH, Jobling S, Brennan K, Headon DJ. Enhanced Edar signalling has pleiotropic effects on craniofacial and cutaneous glands. PloS one. 2009;4(10):e7591 (Epub 2009/10/27).

16. Cui CY, Smith JA, Schlessinger D, Chan CC. X-linked anhidrotic ectodermal dysplasia disruption yields a mouse model for ocular surface disease and resultant blindness. Am J Pathol. 2005;167(1):89-95 (Epub 2005/06/24).

17. Wang YC, Li S, Chen X, Ma B, He H, Liu T, et al. Meibomian gland absence related dry eye in ectodysplasin a mutant mice. Am J Pathol. 2016;186(1):32-42 (Epub 2015/12/03).

18. Lin $\mathrm{MH}, \mathrm{Hsu} \mathrm{FF}, \mathrm{Miner} \mathrm{JH}$. Requirement of fatty acid transport protein 4 for development, maturation, and function of sebaceous glands in a mouse model of ichthyosis prematurity syndrome. J Biol Chem. 2013;288(6):3964-76 (Epub 2012/12/ 29). 
19. McMahon A, Lu H, Butovich IA. A role for ELOVL4 in the mouse meibomian gland and sebocyte cell biology. Invest Ophthalmol Vis Sci. 2014;55(5):2832-40 (Epub 2014/03/29).

20. Fujii M, Shimazaki Y, Muto Y, Kohno S, Ohya S, Nabe T. Dietary deficiencies of unsaturated fatty acids and starch cause atopic dermatitis-like pruritus in hairless mice. Exp Dermatol. 2015;24(2):108-13 (Epub 2014/11/13). 